\title{
Wheeze in preschool children: who is followed-up, who is treated and who is hospitalized?
}

\author{
D.K. Luyt*, A.M. Bourke*, P. Lambert**, P. Burton**, H. Simpson*
}

\begin{abstract}
Wheeze in preschool children: who is followed-up, who is treated and who is hospitalized? D.K. Luyt, A.M. Bourke, P. Lambert, P. Burton, H. Simpson. (CERS Journals Ltd 1995.

ABSTRACT: This study determined the proportions of children $\leq \mathbf{5}$ yrs of age with reported wheeze who were undergoing medical follow-up, receiving anti-asthma medication, or admitted to hospital; and investigated factors important in determining which children would receive these treatments. The symptomatic children represented a wheeze prevalence of $16 \%$ of the study sample of 1,422 children.

The cumulative incidence of treatment and hospitalization and point prevalence of current medical follow-up were determined using a parent-answered postal questionnaire study of a population-based random sample of 222 children. Odds ratios (OR) were calculated for wheeze severity, environmental, social, familial and demographic factors found to affect the likelihood of these treatment end-points.

Among 222 children with wheeze, 99 (35\%) were under current medical review, $165(75 \%)$ had received medication, and $48(22 \%)$ reported being hospitalized. Current follow-up was more likely in girls (OR 2.22; 95\% confidence interval $(95 \%$ CI) 1.12-4.38), with more than three attacks of wheeze in the last year (OR 17.44; 95\% CI 5.22-58.3), or with a household pet (cat or $\mathrm{dog}$ ) where inhalants were wheeze precipitants (OR 13.65; 95\% CI 3.16-58.94). Treatment became more likely in older children (OR 3.91; 95\% CI 1.10-12.71), with inhalants as wheeze precipitants (OR 4.66; 95\% CI 1.08-20.14) or with a household pet (OR 2.28; 95\% CI 1.04-5.03). Hospitalization was less likely with frequent wheeze (OR $0.30 ; 95 \%$ CI 0.12-0.77), but more likely if shortness of breath occurred with wheeze.

Medical follow-up and treatment are related to wheeze severity and exposure to inhaled precipitants, whereas hospital admission occurred in children with attacks causing shortness of breath, and with decreasing frequency of attacks per year. Eur Respir J., 1995, 8, 1736-1741.
\end{abstract}

Depts of *Child Health and **Community Medicine, University of Leicester, Leicester, UK.

Correspondence: D.K. Luyt

P.O. Box 17023

Hillbrow 2038

South Africa

Keywords: Child

hospital admission

treatment

wheeze

Received: January 271995

Accepted after revision June 251995
In a population-based epidemiological study of 1,650 children aged $\leq 5$ yrs we have previously reported the prevalence of wheeze and recurrent cough [1], and the severity characteristics of wheeze, including its relationship with doctor diagnosed asthma [2]. Other studies have emphasized the increasing prevalence of childhood wheeze and asthma [3, 4], the underdiagnosis and undertreatment of children with asthma [5-8], and the striking increase in hospital admission rates for preschool children during recent years [9-11]. The explanation for the increased hospital admission rates observed remains controversial, and it has been suggested that an increase in the severity of wheezing illnesses may be in part responsible $[9,10]$. Our respiratory questionnaire included questions relating to wheeze severity factors as well as the management and hospital admissions for preschool children with wheezing illness. In addition, we collected information relating to a range of demographic, environmental and familial factors. In the present study, we have investigated how these factors (including measures of wheeze severity) influence the probabilities of ongoing medical review, receipt of medication (ever), and hospital admission for children with these illnesses. We also wanted to see if these factors would act similarly in influencing each of the three outcomes.

\section{Methods}

The children investigated were the $1,422(86 \%)$ respondents from a cohort of 1,650 preschool children aged $\leq 5$ yrs, who were identified in a respiratory questionnaire study conducted during 1990 in Leicestershire, UK. The sample and its ascertainment have been described previously [1]. Parents of 222 children who reported at least one episode of wheeze were asked additional questions about management based upon those in the proposed standardized questionnaire of the American Thoracic Society [12], and other previously validated questionnaires $[13,14]$. In order to investigate the health-care received by this group, three principal binary outcome measures were considered.

1) On-going medical review. Children whose parents answered yes to the question: "Does your child attend a 
clinic or see a doctor for wheezing (or asthma)?" were considered as receiving on-going medical review.

2) The receipt of asthma medication. Children whose parents answered yes to the question: "Has your child ever taken any medicine for wheezing (or asthma)?" were considered to have received asthma medication.

3) Hospital admissions. Children whose parents answered yes to the question: "Has your child ever been admitted to hospital with wheezing (or asthma)?" were viewed as having a history of asthma-related hospitalization.

The repeatability of these three questions has previously been demonstrated to be acceptable with Cohen's Kappa (percentage agreement) values of 0.65 (96\%), 0.74 $(93 \%)$ and $0.85(99 \%)$, respectively. These were estimated from a random sample of 100 repeated questionnaire administrations 6 months after the initial survey [1].

As previously described $[1,2]$ the questionnaire investigated measures of wheeze severity, demographic details, the indoor environment, and factors suggestive of a family history of atopy. The (explanatory) factors investigated as being potentially associated with the principal outcome measures are shown in table 1 .

\section{Statistical analysis}

Bivariate relationships between categorical variables were described using contingency tables. Odds ratios (OR) and 95\% confidence intervals $(95 \% \mathrm{CI})$ were calculated using the method described by CLAYTON and HILLS [15]. Formal tests of statistical significance were based upon the Chi-squared test for homogeneity (without continuity correction) or, where stated, the Chi-squared test

Table 1. - Variables investigated in a bivariate and multivariate analysis

\section{Variable}

\section{Gender}

Age group

Total number of subsequent attacks of wheeze

Number of attacks of wheeze in the last year

Length of time since last wheezing attack

Average duration of wheeze attacks

Shortness of breath during wheeze attacks

Nocturnal worsening of wheeze

Seasonal variation of wheeze

Recurrent coughing without a cold

Coughing with a cold

Colds as a precipitant of wheeze

Any precipitants of wheeze other than colds

Wheeze precipitated by exercise

Wheeze precipitated by ingestants

Wheeze precipitated by inhalants (animal hair, dust or grass pollen)

Urban/rural domicile

Socioeconomic status

Parental smoking (paternal, maternal and maternal during pregnancy)

Personal history of eczema

Family history of atopy (including asthma)

Presence of damp or mould at home

Child's bedroom window open at night for linear trend [16] and were carried out in Statistical Analysis System (SAS) [17].

Because the various explanatory factors were likely to be correlated with one another, unconditional logistic regression modelling was used to investigate the multivariate relationship between these factors and each of the binary response (outcome) variables. Modelling was performed using GLIM 3.77 [18]. In each case, model construction was based upon the systematic addition of covariates to an initially null model. Formal tests of the significance of the improvement of fit following the addition of the regression terms relating to specific variables were based upon the likelihood ratio test [19]. Before drawing definitive conclusions, all models were subjected to standard model-checking procedures, including tests for nonlinearity and interaction, the analysis of Pearson residuals and the investigation of leverage [9].

The principal analysis included the age of the child at the completion of the questionnaire as a five level categorical variable (taking the values 1 (age $<1$ year); 2 (1 yr $\leq$ age $<2$ yrs); ...; 5 (age $\geq 4$ yrs). Further models were constructed using precise decimal age and age ${ }^{2}$, but the principal inferences arising from these secondary models were qualitatively so similar to those from the original analysis that only the latter are presented. In order to simplify comparisons between the three outcome measures with the previous results we have reported for doctor-diagnosed asthma [2], "number of attacks during the last year" was used as a marker of wheeze frequency rather than "total number of (subsequent) attacks." In any case, the two measures were very strongly related to one another and inclusion of total number of attacks in the final models did not qualitatively affect the main conclusions.

The study was approved by the Leicestershire Health Authority's committee on the Ethics of Clinical Research Investigation.

\section{Results}

Of the 1,422 preschool children, $125(9 \%)$ wheezed and had been diagnosed by a doctor as having asthma, $97(7 \%)$ wheezed but had no diagnosis of asthma and $31(2 \%)$ had a diagnosis of asthma with cough as the sole symptom. Thus, $222(16 \%)$ of the study population wheezed and $156(11 \%)$ had a formal diagnosis of asthma. The analysis is based upon the 222 children with reported wheeze. Of these children, just over one third (77 out of $221=35 \%$, one missing observation) were under current medical review at the time of the study, three quarters (165 out of $220=75 \%$, two missing observations) gave a history of ever having taken asthma medication, and just over one fifth (48 out of 221 $=22 \%$, one missing observation) reported being hospitalized for asthma or wheezing.

Bivariate relationships between the three outcome measures and the explanatory variables shown in table 1 were computed. Ongoing medical review was more likely in girls $(\mathrm{p}=0.006)$. Medical review was also positively related to increasing number of wheezing episodes (total number of attacks and number of attacks 
Table 2. - Bivariate associations between the three principal outcome measures

\begin{tabular}{|c|c|c|c|}
\hline $\begin{array}{l}\text { History of treatment } \\
\text { for wheeze/asthma }\end{array}$ & No & Under current medical review & Yes \\
\hline $\begin{array}{l}\text { No } \\
\text { Yes }\end{array}$ & $\begin{array}{l}95 \%(52 \text { of } 55) \\
56 \%(92 \text { of } 165)\end{array}$ & $\begin{array}{l}\text { OR }=13.75(95 \% \text { CI } 5.15-36.75) \\
\chi^{2} 1=27.466 ; \quad p<0.001 \\
2 \text { missing observations }\end{array}$ & $\begin{array}{l}5 \%(3 \text { of } 55) \\
44 \%(73 \text { of } 165)\end{array}$ \\
\hline $\begin{array}{l}\text { Ever hospitalized for } \\
\text { wheeze/asthma }\end{array}$ & No & Under current medical review & Yes \\
\hline $\begin{array}{l}\text { No } \\
\text { Yes }\end{array}$ & $\begin{array}{l}68 \%(118 \text { of } 173) \\
54 \%(26 \text { of } 48)\end{array}$ & $\begin{array}{l}\text { OR }=1.81(95 \% \text { CI } 0.94-3.47) \\
\chi^{2} 1=3.263 ; p=0.071 \\
1 \text { missing observation }\end{array}$ & $\begin{array}{l}32 \%(55 \text { of } 173) \\
46 \%(22 \text { of } 48)\end{array}$ \\
\hline $\begin{array}{l}\text { Ever hospitalized for } \\
\text { wheeze/asthma }\end{array}$ & No & story of treatment for wheeze/asthma & Yes \\
\hline $\begin{array}{l}\text { No } \\
\text { Yes }\end{array}$ & $\begin{array}{l}27 \%(47 \text { of } 172) \\
17 \%(8 \text { of } 48)\end{array}$ & $\begin{array}{l}\mathrm{OR}=1.88(95 \% \text { CI } 0.82-4.31) \\
\chi^{2} 1=2.274 ; \mathrm{p}=0.132 \\
2 \text { missing observations }\end{array}$ & $\begin{array}{l}73 \%(125 \text { of } 172) \\
83 \%(40 \text { of } 48)\end{array}$ \\
\hline
\end{tabular}

OR: odds ratio; 95\% CI: 95\% confidence interval; $\chi^{21}$ : Chi-squared test for linear trend.

in the past year) $(\mathrm{p}<0.001$ in both cases), and decreasing time since last attack $(\mathrm{p}<0.001)$, was increased with shortness of breath during attacks $(\mathrm{p}<0.001)$, was positively associated with cough without a cold $(\mathrm{p}=0.004)$, the presence of a cat or dog at home $(\mathrm{p}=0.023)$ and wheeze precipitated by inhalants $(\mathrm{p}<0.001)$, but not to the remaining variables. The findings for children who had ever received medication for wheeze or asthma were largely comparable, with significant relationships for increasing age $(p=0.029)$, increasing number of wheezing attacks (total number and number in last year $(\mathrm{p}<0.001$ and $\mathrm{p}=0.003$, respectively), shortness of breath with attacks $(\mathrm{p}<0.001)$, with cough without a cold $(\mathrm{p}=0.023)$, when wheeze was precipitated by inhalants $(\mathrm{p}<0.001)$, and with cat or dog ownership $(\mathrm{p}=0.002)$. Significant relationships for the number of children admitted to hospital were found only with length of time since the last attack $(p=0.003)$, and with shortness of breath during attacks $(\mathrm{p}<0.001)$.

Table 2 shows the bivariate relationships between the three outcome measures. It is clear from this table that there are strong associations between the perceived need for on-going medical review and a history of having ever received medication for asthma. The bivariate relationship between these two measures and hospitalization for wheeze or asthma were all considerably weaker.

Table 3 gives the results of the unconditional logistic regression analysis using current medical review as the

Table 3. - Unconditional logistic regression analysis of current medical review

\begin{tabular}{|c|c|c|c|}
\hline \multicolumn{2}{|l|}{ Parameter } & Coefficient* & $\begin{array}{c}\text { OR } \\
(95 \% \mathrm{CI})\end{array}$ \\
\hline \multicolumn{2}{|l|}{ Intercept } & $-2.946(0.6046)$ & - \\
\hline \multicolumn{4}{|l|}{ Sex } \\
\hline \multicolumn{2}{|l|}{ Male } & - & 1.00 \\
\hline \multirow{2}{*}{\multicolumn{4}{|c|}{$\begin{array}{l}\text { Female } \\
\text { Number of attacks in the last year }\end{array}$}} \\
\hline & & & \\
\hline \multicolumn{2}{|l|}{ None } & - & 1.00 \\
\hline \multicolumn{2}{|l|}{$1-2$} & $1.080(0.6314)$ & $2.94(0.85-10.15)$ \\
\hline \multicolumn{2}{|l|}{$3+$} & $2.859(0.6157)$ & $17.44(5.22-58.30)$ \\
\hline $\begin{array}{l}\text { Cat or dog } \\
\text { ownership }\end{array}$ & $\begin{array}{l}\text { Animals, dust or } \\
\text { grass as a } \\
\text { precipitant }\end{array}$ & & \\
\hline No & No & - & 1.00 \\
\hline No & Yes & $-0.3872(0.4179)$ & $0.68(0.30-1.54)$ \\
\hline Yes & No & $0.4485(0.4961)$ & $1.57(0.59-4.14)$ \\
\hline Yes & Yes & $2.614(0.7462)$ & $13.65(3.16-58.94)$ \\
\hline
\end{tabular}

*: values in parenthesis are SE. OR: odds ratio; $95 \% \mathrm{CI}$ : $95 \%$ confidence interval. 
binary response variable. The important factors identified were gender, the number of attacks in the last year, ownership of a cat or dog, and having inhalants (animals, dust or grass) as a wheeze precipitant. Females were more likely to be receiving on-going medical review. As the number of attacks in the last year increased, so did the likelihood of being under current medical review. There was an important interaction between the factors of pet ownership and inhalants as a wheeze precipitant. This interaction indicated that pet ownership in the absence of inhalants being precipitants of wheeze does not increase the chance of being under current medical review. However, owning a pet when it has been stated that such inhalants do precipitate wheeze is associated with a high proportion receiving medical followup.

Table 4 shows the results of the unconditional logistic regression analysis for treatment of wheeze or asthma. The important factors were age, number of attacks in the last year, cat or dog ownership, and inhalants as a precipitant of wheeze. Increasing age is associated with an increased likelihood of being treated. The number of attacks in the last year is positively associated with the likelihood of receiving treatment. Similar positive relationships are demonstrated for pet ownership and the presence of inhalants as a wheeze precipitant.

Table 5 details the results of the unconditional logistic regression analysis for a history of hospitalization for wheeze or asthma. The important factors were shortness of breath during the last year and the number of attacks during the last year. Shortness of breath with either some or every wheezing attack was associated with an increased likelihood of being hospitalized. Interestingly, there was a strong negative relationship between the number of attacks in the last year and the likelihood of hospitalization, with an increase in the number of attacks leading to a decrease in the likelihood of being hospitalized.

Table 4. - Unconditional logistic regression analysis of treatment for wheeze or asthma

\begin{tabular}{lcl}
\hline Parameter & Coefficient* & $\begin{array}{c}\text { OR } \\
(95 \% \mathrm{CI})\end{array}$ \\
\hline $\begin{array}{l}\text { Intercept } \\
\text { Age }\end{array}$ & $-0.3471(0.5678)$ & - \\
$<1$ year & - & 1.00 \\
$1-1.99$ years & $-0.1891(0.5660)$ & $0.83(0.27-2.51)$ \\
$2-2.99$ years & $0.1109(0.5755)$ & $1.12(0.36-3.45)$ \\
$3-3.99$ year & $0.6593(0.5947)$ & $1.93(0.60-6.20)$ \\
$4+$ yrs & $1.364(0.6014)$ & $3.91(1.20-12.17)$ \\
Number of attacks in the last year & \\
None & - & 1.00 \\
$1-2$ & $0.2714(0.4304)$ & $1.21(0.56-3.05)$ \\
$3+$ & $1.416(0.5065)$ & $4.12(1.53-11.12)$ \\
Do animals, pets or grass make the child wheeze? & 1.00 \\
No & - & $4.66(1.08-20.14)$ \\
Yes & $1.539(0.7469)$ & \\
Does the family have a cat or a dog? & \\
No & - & 1.00 \\
Yes & $0.8279(0.4014)$ & $2.28(1.04-5.03)$ \\
\hline
\end{tabular}

*: values in parenthesis are SE. OR: odds ratio; $95 \%$ CI: $95 \%$ confidence interval.
Table 5. - Unconditional logistic regression analysis of hospital admission for wheeze or asthma

\begin{tabular}{lll}
\hline Parameter & \multicolumn{1}{c}{ Coefficient* } & \multicolumn{1}{c}{$\begin{array}{c}\text { OR } \\
(95 \% \mathrm{CI})\end{array}$} \\
\hline $\begin{array}{ll}\text { Intercept } \\
\text { Number of attacks in the last year }\end{array}$ & \multicolumn{1}{l}{} \\
None & $-1.973(0.518)$ & 1.00 \\
$1-2$ & $-1.073(0.4972)$ & $0.34(0.13-0.91)$ \\
$3+$ & $-1.200(0.4809)$ & $0.30(0.12-0.77)$ \\
Shortness of breath with attacks & 1.00 \\
Never & - & $4.14(1.39-12.3)$ \\
Sometimes & $1.42(0.5560)$ & $17.93(5.70-56.49)$ \\
Always & $2.887(0.5852)$ & \\
\hline
\end{tabular}

*: values in parenthesis are SE. OR: odds ratio; $95 \%$ CI: $95 \%$ confidence interval.

Table 6. - Bivariate associations between the three principal outcome measures and doctor diagnosed asthma

\begin{tabular}{|c|c|c|c|c|c|c|}
\hline & \multicolumn{2}{|c|}{$\begin{array}{l}\text { Under medical } \\
\text { review }\end{array}$} & \multicolumn{2}{|c|}{$\begin{array}{l}\text { Ever treated for } \\
\text { wheeze }\end{array}$} & \multicolumn{2}{|c|}{$\begin{array}{l}\text { Ever hospitalized } \\
\text { for wheeze }\end{array}$} \\
\hline & $\%$ & $\mathrm{n}$ & $\%$ & $\mathrm{n}$ & $\%$ & $\mathrm{n}$ \\
\hline \multicolumn{7}{|c|}{ Doctor diagnosed asthma } \\
\hline No & 13 & 12 of 96 & 51 & 48 of 95 & 12 & 11 of 96 \\
\hline \multirow[t]{4}{*}{ Yes } & 52 & 65 of 125 & 94 & 117 of 125 & 30 & 37 of 125 \\
\hline & \multicolumn{2}{|c|}{$\begin{array}{l}\mathrm{OR}=7.583 \\
(3.95-14.55)\end{array}$} & \multicolumn{2}{|c|}{$\begin{array}{l}\mathrm{OR}=14.320 \\
(7.00-29.29)\end{array}$} & \multicolumn{2}{|c|}{$\begin{array}{l}\mathrm{OR}=3.249 \\
(1.51-6.64)\end{array}$} \\
\hline & \multicolumn{2}{|c|}{$\begin{array}{l}\chi^{2} \mathrm{l}=37.318 \\
\mathrm{p}<0.001\end{array}$} & \multicolumn{2}{|c|}{$\begin{array}{l}\chi^{2} \mathrm{l}=53.411 \\
\mathrm{p}<0.001\end{array}$} & \multicolumn{2}{|c|}{$\begin{array}{l}\chi^{2} \mathrm{l}=10.51 \\
\mathrm{p}=0.001\end{array}$} \\
\hline & \multicolumn{2}{|c|}{$\begin{array}{l}1 \text { missing } \\
\text { observation }\end{array}$} & \multicolumn{2}{|c|}{$\begin{array}{l}2 \text { missing } \\
\text { observations }\end{array}$} & \multicolumn{2}{|c|}{$\begin{array}{l}1 \text { missing } \\
\text { observation }\end{array}$} \\
\hline
\end{tabular}

Values in parenthesis are 95\% CI. OR: odds ratio; $95 \%$ CI: $95 \%$ confidence interval; $\chi^{2} 1$ : Chi-squared test for linear trend.

We have previously described the main characteristics of preschool children with doctor-diagnosed asthma [2]. Table 6 details the bivariate relationships between doctor diagnosed asthma and each of the three principal outcome measures relating to follow-up, treatment and hospitalization. There are significant differences for each outcome measure between those children with, and those without, a formal diagnosis of asthma. Those with a diagnosis of asthma were more likely to be under current medical review, to have ever received medication and to have been hospitalized.

\section{Discussion}

These results present the opportunity to examine the determinants of some important aspects of medical supervision of preschool children with wheeze. These are current medical review, receipt of medication (ever) and admission to hospital. These questions were included in the survey because it was felt that it was important to attempt to quantify this area of health-care in young children, particularly as there have been no validated questionnaires on respiratory symptoms applicable in the 
preschool age-group. Quantification was felt to be particularly important given that the increased occurance of hospitalization in this age group may be due to a possible increase in the severity of wheeze $[9,10]$. Where possible, questions were used which have been shown to exhibit acceptable repeatability $[13,14,20]$. This meant that the data accrued in response to the questions concerning hospitalization and receipt of asthma medication, were able to be interpreted with some confidence.

The question concerning current medical follow-up had not been used in other similar studies and so did not benefit the validation enjoyed by the other two questions. This inevitably limits the interpretation of data concerning current follow-up, and is also limited in scope because the precise nature of follow-up was not explicitly defined. However, the question was shown to have the same high degree of repeatability seen with the other two questions. Furthermore, because of the 6 month lag between the initial and repeatability survey, the answers to this question were likely to concern current (ongoing) medical follow-up.

Some reservations must apply to the question on receipt of medication for wheeze or asthma, because of a lack of detail as to which precise medication had been prescribed. Finally, as both the questions on receipt of medication and hospitalization were retrospective in nature, some caution should be exercised in their interpretation. Despite these reservations, and given the high repeatability of the questions used, the results obtained are likely to provide important insights into which factors are important in influencing the management of young children with wheeze, and furthermore how acute hospitalization is influenced by these same factors.

There was a strong association between current medical review and a history of asthma medication. However, the association of both of these variables with hospitalization was weak and did not reach formal statistical significance.

It is of interest to note that in both bivariate and logistic regression modelling the factors associated with the outcomes of current medical follow-up and ever receiving treatment are broadly similar. Furthermore, the two regression models presented are themselves similar to the previously reported model for doctor diagnosed asthma [2], in that they indicate the importance of wheeze frequency and precipitants of wheeze other than colds. The number of attacks in the last year appeared to increase the chance of both current medical follow-up and treatment. The finding that females are more likely to receive current medical attention may indicate that although wheeze is more common in males, those girls with this symptom are more likely to be severely affected. As current medical follow-up is a measure of point prevalence, it is not surprising that age is not an important determinant. However, when considering ever being treated for wheeze or asthma, the association of age is positive, since it is formally a measure of cumulative incidence.

Precipitants of wheeze other than colds are important in both regression models although they act in slightly different ways. For children in whom inhalants are not a reported precipitant of wheeze, owning a cat or dog did not increase the likelihood of being under current medical review. However, in those children for whom inhalants are a precipitant, ownership of a cat or dog was associated with an increased probability of current medical review. On the other hand, pet ownership appeared to be associated with an increased probability of having required treatment for wheeze or asthma, regardless of whether inhalants were a precipitant or not. The reason for this is not clear and it may simply reflect inadequate statistical power to resolve an interaction in the case of the treatment outcome. However, it may also indicate that some parents are unaware that the family pet could be a cause of wheeze in their child. This reinforces the need to take a detailed social and environmental history when assessing children with wheeze. Shortness of breath with wheezing attacks does not appear to predict the treatment or follow-up outcomes. This is because information on wheeze severity is adequately described by the number of attacks in the last year.

The factors which are associated with hospital admission contrast sharply with those of medical follow-up and treatment. Shortness of breath during attacks of wheeze greatly increase the likelihood of admission. This inference is logical as it is a descriptor of severity during a wheezing attack (most other variables being either markers of wheeze frequency or precipitants of wheeze). Interestingly, the number of attacks in the last year was negatively associated with the likelihood of hospitalization, as a greater degree of wheeze frequency is associated with a decreased likelihood of hospitalization. One interpretation of this is that there is a "training effect", in that the parents of a child with frequent attacks are more used to coping with acute wheeze in their child. Thus, it is children who suffer infrequent attacks or have attacks which render them short of breath who are at greater risk of hospitalization. Although most children with wheeze or asthma are never likely to require hospitalization, an attack leading to admission to hospital could potentially come quite unexpectedly for almost any child, regardless of their overall symptom profile and perceived need for on-going review or treatment. Furthermore, although a significantly greater proportion of wheezy children who had a formal asthma diagnosis required hospitalisation, the absence of such a diagnosis is no guarantee that a severe attack will not occur.

Our data support this assertion; despite the strong associations between having a formal asthma diagnosis and both current medical review and having ever received medication for wheeze or asthma, the relationship between asthma diagnosis and hospitalization was less pronounced, although still statistically significant. However alternative explanations exist. It could be that hospital admissions for wheeze or asthma in the youngest age-groups, where wheezing and its various causes are less well-defined, might have been subject to spurious reporting. In order to investigate this possibility, the analysis was repeated firstly excluding children aged under $1 \mathrm{yr}$, and then children aged under 2 yrs. In neither instance were the principal results qualitatively changed. Our modelling could only be based upon those 
children who reported wheeze and, therefore, we can make no inferences about the factors influencing the management of asthmatic children with cough as the sole symptom. In our population 31 out of $1,422(2 \%)$ were diagnosed asthmatic on the basis of cough alone.

If our interpretation of the data is correct, there are considerable clinical and public health implications. Given the concern that hospital admissions for asthma have increased [9-11], these results suggest that any intervention to address this problem must be targeted at all wheezy children and not just those who are most severely affected. Thus, any strategies to improve the health of childhood asthmatics must include all wheezy children, not just those with frequent symptoms or a diagnosis of asthma.

\section{References}

1. Luyt DK, Burton P, Simpson H. An epidemiological study of wheeze, doctor-diagnosed asthma and cough in preschool children in Leicestershire. Br Med J 1993; 306: 1386-1390.

2. Luyt DK, Burton P, Brooke AM, Simpson H. Wheeze in preschool children and its relation with doctor-diagnosed asthma. Arch Dis Child 1994; 71: 24-30.

3. Anderson HR Butland BK, Strachan DP. Trends in prevalence and severity of childhood asthma. Br Med J 1994; 308: 1600-1604.

4. Peat JK, Van den Berg RH, Green WF, Mellis CM, Leeder SR, Woolcock AJ. Changing prevalence of asthma in Australian children. Br Med J 1994; 308: 15911596.

5. Speight ANP, Lee DA, Hay EN. Underdiagnosis and undertreatment of asthma in childhood. Br Med J 1983; 286: 1253-1257.

6. Anderson HR, Bailey PA, Cooper JC, West S. Morbidity and school absence caused by asthma and wheezing illness. Arch Dis Child 1983; 58: 777-784.

7. Levy M, Bell L. General practice audit of asthma in childhood. Br Med J 1984; 289: 1115-1116.

8. Conway SP, Littlewood JM. Admission to hospital with asthma. Arch Dis Child 1985; 60: 636-639.

9. Anderson HR. Increase in hospitalisation for childhood asthma. Arch Dis Child 1978; 53: 295-300.

10. Mitchell EA. International trends in hospital admission rates for asthma. Arch Dis Child 1985; 60: 376378.

11. Hyndman SJ, Williams DRR, Merrill SL, Lipscombe JM, Palmer CR. Rates of admission to hospital for asthma. Br Med J 1994; 308: 1596-1600.

12. Ferris BG. Epidemiological standardisation project. Am Rev Respir Dis 1978; 118: 1-120.

13. Clifford RD, Radford M, Howell JB, Holgate ST. Prevalence of respiratory symptoms among 7 and 11 year old school children and association with asthma. Arch Dis Child 1989; 64: 1118-1125.

14. Salome CM, Peat JK, Britton WJ, Woolcock AJ. Bronchial hyperresponsiveness in two populations of Australian school children. I. Relation to respiratory symptoms and diagnosed asthma. Clin Allergy 1987; 17: 271281.

15. Clayton D, Hills M. In: Statistical Models in Epidemiology. Oxford, Oxford University Press, 1993.

16. Armitage P, Berry G. In: Statistical Methods in Medical Research. 2nd Edn. Oxford, Blackwell Scientific, 1987.

17. SAS (Statistical Analysis System). North Carolina: SAS Institute Inc., 1985.

18. Aitken M, Anderson D, Francis B, Hinde J. In: Statistical Modelling in GLIM. Oxford, Oxford University Press, 1989.

19. McCullagh P, Nelder JA. In: Generalised Linear Models. 2nd Edn. London, Chapman and Hall, 1989.

20. Brunekreef B, Groot B, Fijcken G, Hoek A, Steenbekker A, de Boer P. Reproducibility of childhood respiratory symptom questions. Eur Respir J 1992; 5: 930-935. 